\title{
The effect of infusion rate and catheter length on the temperature of warming fluid
}

\author{
Seong Ho Lee, Hae Kyu Kim, Sung Chun Park, Eun Soo Kim, Tae Kyun Kim, and Chae Sun Kim* \\ Department of Anesthesiology and Pain Medicine, Pusan National University Hospital, Pusan, *Masan Samsung Hospital, Masan, \\ Korea
}

Background: We used warming fluid for maintenance of body temperature in operating room or intensive care unit. This study was aimed to investigate the effect of infusion rate and catheter length on the temperature of warming fluid. Methods: Normal saline was used for testing infusion and temperature of infusion was maintained by a warmer as $40^{\circ} \mathrm{C}$. The temperatures of solution in infusion line were measured at $0,25,50,75$, and $100 \mathrm{~cm}$ apart from warmer at six different flow rates $(100,200,300,700,1,400$, and 2,100 m//h). We also measured the temperature changes at room temperature (RT) and $5^{\circ} \mathrm{C}, 10^{\circ} \mathrm{C}$, and $15^{\circ} \mathrm{C}$ above RT. Results: The time to maintain solution temperature as $40^{\circ} \mathrm{C}$ was $165,122,37,37,21$, and $19 \mathrm{~s}$ at flow rate 100, 200, 300, 700, 1,400 , and $2,100 \mathrm{ml} / \mathrm{h}$. The peak temperature was $43.58 \pm 0.58,44.43 \pm 1.18,44.37 \pm 0.70,43.79 \pm 0.61,42.82 \pm$ 0.97 , and $42.11 \pm 0.92^{\circ} \mathrm{C}$ according to increasing flow rate. The temperature at $100 \mathrm{~cm}$ apart from warmer was $23.96 \pm 1.53,25.46 \pm 2.76,29.32 \pm 3.47,31.40 \pm 5.38,31.39 \pm 6.75$, and $38.14 \pm 0.96^{\circ} \mathrm{C}$ according to increasing flow rate. Conclusions: These results suggested that the decreasing rate of temperature was related inversely to the flow rate and directly to the catheter length. There may be needed a rapid infusion pump with adequate heating system at a high flow rate and to locate the warmer close to patient for reserving a heating effect. (Korean J Anesthesiol 2010; 58: 31 37)

\section{Key Words: Fluid temperature, Infusion rate, Warmer.}

\section{Introduction}

In a cold environment or patients with hypothermia, many studies have examined the methods for using warm fluids [1].
In cases in which the temperature of fluids was not increased close to the body temperature and a massive amount of cool fluids were administered or during the cool period of summer or winter, a hypothermia can frequently occur. Human bodies generate the heat within the body and their

Received: August 21, 2009. Revised: 1st, August 28, 2009, 2nd September 25, 2009. Accepted: October 23, 2009.

Corresponding author: Hae Kyu Kim, M.D., Department of Anesthesiology and Pain Medicine, Pusan National University Hospital, 10, Amidong 1-ga, Seo-gu, Busan 602-739, Korea. Tel: 82-51-240-7391, Fax: 82-51-242-7466, E-mail: hakykim@pusan.ac.kr

(c) This is an open-access article distributed under the terms of the Creative Commons Attribution Non-Commercial License (http:// creativecommons.org/licenses/by-nc/3.0/), which permits unrestricted non-commercial use, distribution, and reproduction in any medium, provided the original work is properly cited. 
capability to elevate the central temperature disappears at a temperature of $30-32^{\circ} \mathrm{C}$ [2]. Accordingly, a substantial extent of the interest has been given to the maintenance of body temperature at an operation room or an intensivecare-unit (ICU). It is difficult to raise the temperature by using fluids whose temperature was increased. Due to cool fluids, however, a lowering of the body temperature may occur. An administration of fluids $1 \mathrm{~L}$ at room temperature may reduce a mean temperature by approximately $0.25^{\circ} \mathrm{C}$. A hypothermia occurs in approximately $60 \%$ of patients with trauma or those who were surgically treated $[3,4]$. A hypothermia causes the occurrence of many side effects. In patients who developed hypothermia, if the hemodynamically stable status should be maintained, a greater deal of fluids than general cases would be required. Due to the concurrent presence of side effects, the oxygen demand of heart is increased and this may lead to the acute death [5]. In cases in which the body temperature was lower than $33^{\circ} \mathrm{C}$, the supraventricular arrythmias may occur. In cases in which it was lower than $28^{\circ} \mathrm{C}$, the ventricular fibrillation occurs. Owing to this, most cases may lead to the death. Accordingly, an appropriate prevention would be mandatory. When the side effects occurred, the treatment should be performed during the shortest period of time [6]. In cases in which the optimal body temperature could not be maintained clinically and it was decreased to $<36^{\circ} \mathrm{C}$, there may be problems such as the increased incidence of infection, cardiac problems, blood coagulation problems, an increased length of hospital stay and the increased medical expense [7-9].

Several methods for increasing the temperature for the adjustment of fluids have been proposed up to present. In a battle field setting which is exposed to the external environment, there are methods that chemical thermogenic packs are generally used to heat an emergency food or those that an immersion in a hot water is attempted [1]. Besides, methods for increasing the temperature of fluids using an ultra-high frequency wave have also been proposed [10]. An administration of fluids whose temperature was increased using a heater to patients with severe trauma or those who were surgically treated has been already generalized [11].

It could not be determined that all the measures were taken to protect the body temperature immediately although a heater was used. Unless there should be the consideration of the effects of factors due to the adjacent environment where the clinical behavior is conducted on the temperature of fluids which are administered to the body, there would be a lack of the help for actually maintaining the body temperature. There are also reports that a heater should be used in cases in which the mean body temperature is expected to decrease by more than $0.5-1.0^{\circ} \mathrm{C}[12]$. Accordingly in the current study, in cases in which heated fluids are administered using a heater in such a condition as the exposure to a room temperature, attempts are made to evaluate the changes in the temperature of fluids according to the flow rate and the length of venous line.

\section{Materials and Methods}

Fluids which were used in the current study were a purified solution, which was a saline (ChoongWae Pharmaceutical Corp, Seoul, Korea) that is commonly used at an operation room, a ward and an ICU. In regard to a flow rate which was examined, in the anesthetic management at an operation room, based on $10 \mathrm{ml} / \mathrm{kg} / \mathrm{h}$ corresponding to the general maintenance of upper abdominal surgery in patients weighed $10 \mathrm{~kg}, 20 \mathrm{~kg}, 30 \mathrm{~kg}$ and $70 \mathrm{~kg}$, patients were divided into the following groups: $100(\mid-100$ group, $n=10), 200(\mid$ -200 group, $n=10), 300(\mid-300$ group, $n=10)$ and $700 \mathrm{ml} /$ h $(I-700$ group, $n=10)$. Including these groups, there were also six groups containing two groups corresponding to 2- to 3-times higher than the maintenance dose in adult patients weighed $70 \mathrm{~kg}: 1,400(I-1,400$ group, $\mathrm{n}=10)$ and 2,100 (I2,100 group, $n=10) \mathrm{ml} / \mathrm{h}$. Besides, at a various temperature of the fluids, to examine the changes in the temperature of fluids which are infused via a venous line, in the room temperature (A) group $(n=40)$, the room temperature $+1^{\circ} \mathrm{C}$ (B) group $(n=40)$, the room temperature $+5^{\circ} \mathrm{C}(\mathrm{C})$ group $(\mathrm{n}$ $=40)$, the room temperature $+10^{\circ} \mathrm{C}(\mathrm{D})$ group $(\mathrm{n}=40)$, the room temperature $+15^{\circ} \mathrm{C}(\mathrm{E})$ group $(n=40)$, the fluids were flown at a velocity of $700 \mathrm{ml} / \mathrm{h}$ via a venous line. Meanwhile, the changes in the temperature of fluids were measured.

Methods which were used in the current study were based on those which were implemented by Jung et al. [13]. A heater was a blood heater product as well as a portable prompt fluid (Joyother BM-1 ${ }^{\circledR}$, Joyother, Seoul, Korea). A brief description of the methods can be made as follows: Fluid agents were placed in a folder and this was connected to a venous line. Then, this passed through an infusion pump (TERUMO STC-503 Pump I/V InfusionTM, Terumo Medical Corporation, Somerset, New Jersey, USA). Thus, the regulation was done at a variable flow rate. A selection of the flow rate was randomly determined using a randomization table. To accurately measure the heating performance of a product, prior to measuring the forthcoming flow rate, the product was rinsed with fluids at room temperature. Until a heating plate was cooled at a room temperature, the following temperature measurement was repeated. Several flow rates were measured using a heating plate and then discarded. Using another heating plate, the experimental procedure was repeated.

When the flow rate of $>1,000 \mathrm{ml} / \mathrm{h}$ was measured, a multiple number of infusion pumps were connected in a row in three ways. Thus, it was assured that infusion pumps were escaped to a single venous line. In the middle of it, a heater was placed. A temperature sensor was connected to a data 
acquisition and a serial data transmitter module (TLOG-1000 System $^{\mathrm{TM}}$, Carvolab, Inc., Bucheon, Korea) for the automatic temperature recording through a thermocouple. Then, using a software programme (SDLOG' ${ }^{\mathrm{TM}}$, Carvolab, Inc., Bucheon, Korea), the thermal changes were automatically measured depending on each channel in a sequential manner. TLOG1000 System $^{\text {TM }}$ has a total of six channels, each of which contains anode and cathode. It displays a temperature data on an LCD screen at a 1-second interval on a real-time basis. A temperature-measuring sensor was installed in a total of four locations prior to and following a heater via a venous line, i.e., immediately before an entry into a heater, immediately after an entry into a heater and at 25, 50, 75 and $100 \mathrm{~cm}$ following the passage. Here, the measurement of room temperature was done using a measuring device which was placed outside of a machine. A venous line was not covered with a heatsealing medium, but it was exposed outside. Thus, it was assured that the changes in the temperature of fluids could be subject to the external temperature.

A statistical analysis was performed using StatView Program (version 5.0 SAS Institute Inc, Cary, NC, USA), by which a comparison was made for the difference in the temperature depending on the flow rate and the degree of temperature loss using a t-test. Statistical significance was set at $P<0.05$.

\section{Results}

The room temperature at which the experiment was performed was $26.73 \pm 0.01{ }^{\circ} \mathrm{C}$ and the temperature of

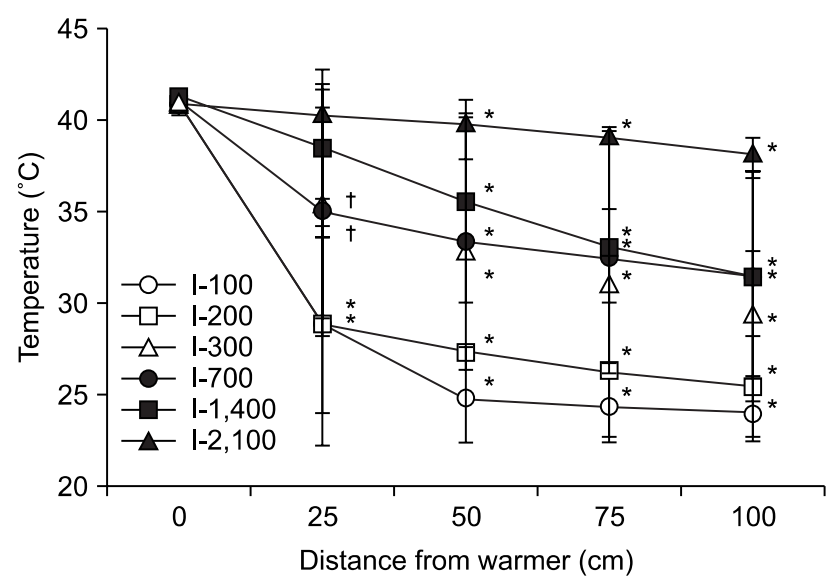

Fig. 1. The temperatures in each groups were decreased according to the distance from warmer. The temperature was effectively maintained at 2,100 ml/h but temperatures in $1-100$ and 200 groups were rapidly decreased than others. I-100 group: infusion rate 100 $\mathrm{ml} / \mathrm{h}, \mathrm{l}-200$ group: infusion rate $200 \mathrm{ml} / \mathrm{h}, \mathrm{l}-300$ group: infusion rate $300 \mathrm{ml} / \mathrm{h}, \mathrm{l}-700$ group: infusion rate $700 \mathrm{ml} / \mathrm{h}, \mathrm{l-1}, 400$ group: infusion rate $1,400 \mathrm{ml} / \mathrm{h}, \mathrm{I}-2,100$ group: infusion rate $2,100 \mathrm{ml} / \mathrm{h}$. ${ }^{*}$ means $P<$ 0.01 compared with temperature of $0 \mathrm{~cm}$ from warmer, ${ }^{\dagger}$ means $\mathrm{P}$ $<0.05$ compared with temperature of $0 \mathrm{~cm}$ from warmer. fluids was $24.86 \pm 0.02^{\circ} \mathrm{C}$. The time that elapsed until the temperature consistently reached a value of approximately $40^{\circ} \mathrm{C}$ in such orders as $1-100,1-200,1-300,1-700,1-1,400$ and $I-2,100$ was 165 seconds, 122 seconds, 37 seconds, 37 seconds, 21 seconds and 19 seconds on average. A heating temperature was increased in a flow-rate-depenent manner. The maximal outlet temperature was $43.58 \pm 0.58^{\circ} \mathrm{C}$ in the I -100 group and $44.43 \pm 1.18^{\circ} \mathrm{C}$ in the $\mathrm{I}-200$ group. Besides, it was also $44.37 \pm 0.70^{\circ} \mathrm{C}$ in the $1-300$ group, $43.79 \pm 0.61^{\circ} \mathrm{C}$ in the $\mathrm{I}-700$ group, $42.82 \pm 0.97^{\circ} \mathrm{C}$ in the $\mathrm{I}-1,400$ group and $42.11 \pm 0.92^{\circ} \mathrm{C}$ in the $\mathrm{I}-2,100$ group. Cases in which the outlet temperature was the highest were shown to be $46.29^{\circ} \mathrm{C}$ at an infusion rate of $200 \mathrm{ml} / \mathrm{h}$. Of these, the maximal outlet temperature was maintained at $<2$ seconds in most cases.

In regard to the maximal outlet temperature, as compared with the $1-2,100$ group, there were significant differences between the $1-100$ group $(P<0.05)$, the $1-200$ group $(P<$ 0.01 ), the $1-300$ group $(P<0.01)$ and the $1-700$ group ( $P$ $<0.01$ ). In addition, between the $1-1,400$ group, the $I-200$ group ( $P<0.05$ ) and the $I-300$ group $(P<0.05)$, there were also significant differences.

At an outlet temperature, the degree of temperature lowering depending on the flow rate was measured. According to this, as the flow rate was relatively higher, the temperature was well maintained. In an outlet of a heater, the overall temperature of fluids was $40.99 \pm 0.44^{\circ} \mathrm{C}$ on average. There was no inter-group difference. The temperature of fluids was also measured in the areas which were remote $1 \mathrm{~m}$ from an outlet, and it was $23.96 \pm 1.53^{\circ} \mathrm{C}$ in the $\mathrm{I}-100$ group, 25.46

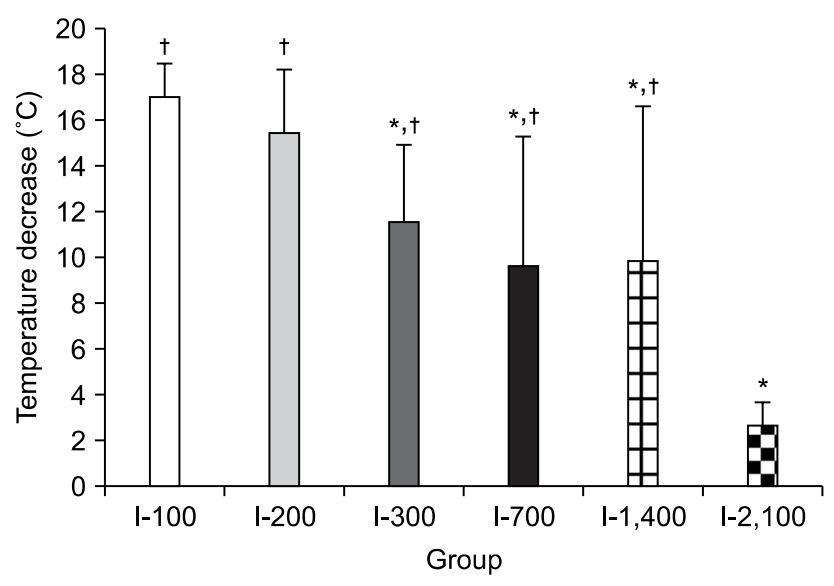

Fig. 2. The decrease of fluid temperature at $100 \mathrm{~cm}$ after warmer in each groups was inversely related to the infusion rate. The temperature was effectively maintained at 2,100 $\mathrm{ml} / \mathrm{h}$ but temperature at $100 \mathrm{ml} / \mathrm{h}$ was rapidly decreased. I-100 group: infusion rate $100 \mathrm{ml} / \mathrm{h}, \mathrm{l}-200$ group: infusion rate $200 \mathrm{ml} / \mathrm{h}, \mathrm{l}-300$ group: infusion rate $300 \mathrm{ml} / \mathrm{h}, \mathrm{l}-700$ group: infusion rate $700 \mathrm{ml} / \mathrm{h}$, I-1,400 group: infusion rate 1,400 $\mathrm{ml} / \mathrm{h}, \mathrm{l}-2,100$ group: infusion rate $2,100 \mathrm{ml} / \mathrm{h}$. ${ }^{*}$ means $\mathrm{P}<0.01$ compared with $\mathrm{l}-100$ group, ${ }^{\dagger}$ means $\mathrm{P}$ $<0.01$ compared with $\mathrm{l}-2,100$ group. 


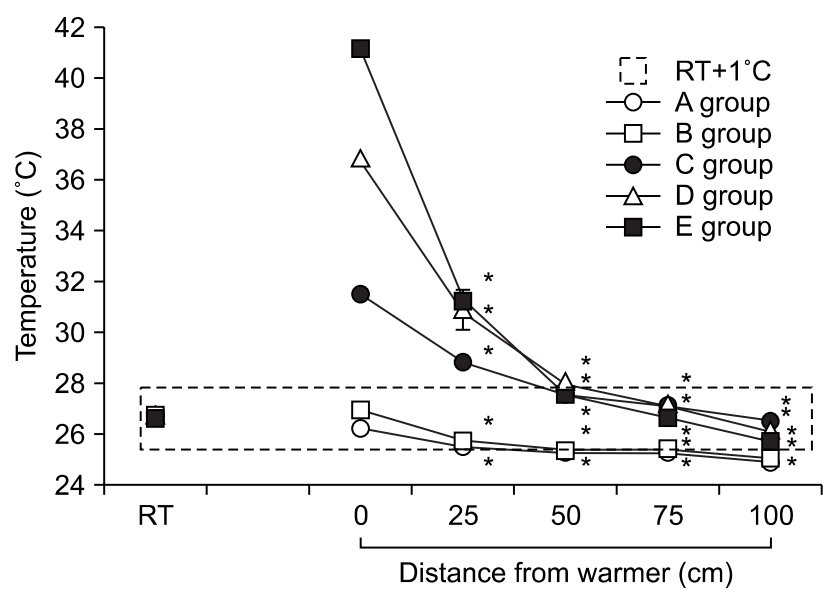

Fig. 3. The temperatures in each groups decreased within room temperature (RT) $\pm 1{ }^{\circ} \mathrm{C}$ at $50 \mathrm{~cm}$ after warmer for $700 \mathrm{ml} / \mathrm{h}$ of infusion rate. $\mathrm{A}$ group and $\mathrm{B}$ group rapidly approached to the lower temperature than RT at $25 \mathrm{~cm}$ after warmer. The temperatures in all groups showed lower than RT at $100 \mathrm{~cm}$ after warmer $(\mathrm{P}<$ 0.01). A group: $R T, B$ group: $R T \pm 1{ }^{\circ} \mathrm{C}, \mathrm{C}$ group: $\mathrm{RT} \pm 5^{\circ} \mathrm{C}, \mathrm{D}$ group: $\mathrm{RT} \pm 10^{\circ} \mathrm{C}, \mathrm{E}$ group: $\mathrm{RT} \pm 15^{\circ} \mathrm{C}$. ${ }^{*}$ means $\mathrm{P}<0.01$ compared with temperature of $0 \mathrm{~cm}$ from warmer.

$\pm 2.76^{\circ} \mathrm{C}$ in the $1-200$ group, $29.32 \pm 3.47^{\circ} \mathrm{C}$ in the $1-300$ group, $31.40 \pm 5.38^{\circ} \mathrm{C}$ in the $1-700$ group, $31.39 \pm 6.75^{\circ} \mathrm{C}$ in the $I-1,400$ group and $38.14 \pm 0.96^{\circ} \mathrm{C}$ in the $I-2,100$ group (Fig. 1, P $<0.01$ ). During the progression for this distance, as the flow rate was increased, the temperature distance was shown to be $17.03 \pm 1.43^{\circ} \mathrm{C}, 15.44 \pm 2.82^{\circ} \mathrm{C}, 11.59 \pm 3.32^{\circ} \mathrm{C}$, $9.65 \pm 5.61^{\circ} \mathrm{C}, 9.85 \pm 6.77^{\circ} \mathrm{C}$ and $2.71 \pm 0.97^{\circ} \mathrm{C}$. These results indicate that a heat loss was decreased (Fig. 2).

According to the experiment which was performed to confirm a heat loss at various flow rates, at initial temperatures of $26.19 \pm 0.04^{\circ} \mathrm{C}$ in the group $\mathrm{A}, 26.96 \pm 0.02^{\circ} \mathrm{C}$ in the group $\mathrm{B}, 31.52 \pm 0.12^{\circ} \mathrm{C}$ in the group $\mathrm{C}, 36.82 \pm 0.15^{\circ} \mathrm{C}$ in the group $D$ and $41.18 \pm 0.06^{\circ} \mathrm{C}$ in the group $\mathrm{E}_{\text {, depending }}$ on the length of a venous line of $1 \mathrm{~m}$, the temperature lowering showed a great degree of the heat loss as the difference from a room temperature was relatively greater because the initial temperature was relatively higher (Fig. 3). Besides, according a linear regression method, the estimated temperature depending on the length of a venous line and the temperature of infused fluids was calculated as follows:

(1) Temperature $=25.986-0.012 \times$ the length of a venous line $(R 2=0.61)($ Group $A)$

(2) Temperature $=26.55-0.016 \times$ the length of a venous line $(R 2=0.726)($ Group B)

(3) Temperature $=30.679-0.047 \times$ the length of a venous line $(R 2=0.596)($ Group C)

(4) Temperature $=34.765-0.1 \times$ the length of a venous line $(R 2=0.672)($ Group D)

(5) Temperature $=37.582-0.142 \times$ the length of a venous line (R2 = 0.729) (Group E) (Fig. 4).
Bivariate scattergram with regression split by: group

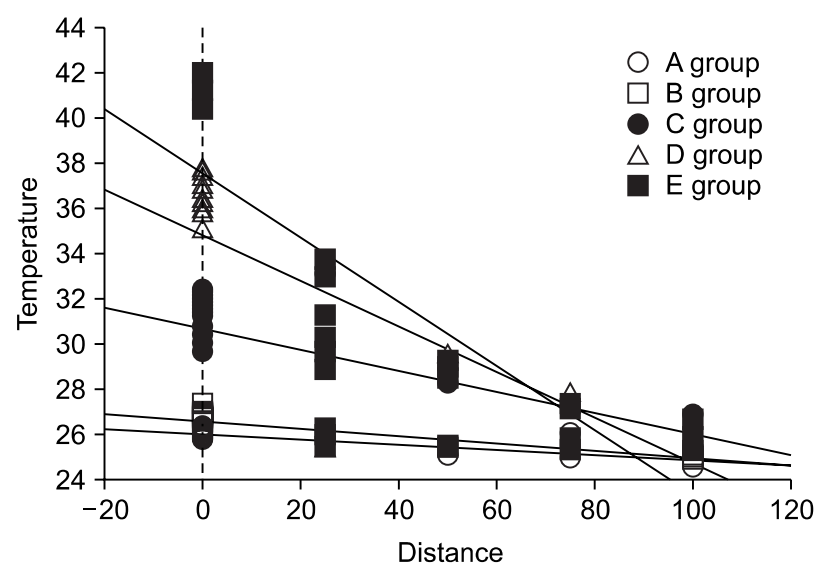

Temperature $=25.986-.012 \times$ Distance: $R^{2}=.81$ (A group) Temperature $=26.55-.018 \times$ Distance $: R^{2}=.726(B$ group $)$ Temperature $=30.679-.047 \times$ Distance: $R^{2}=.596(C$ group $)$ Temperature $=34.765-.1 \times$ Distance: $R^{2}=.672(D$ group $)$ Temperature $=37.582-.142 \times$ Distance: $R^{2}=.729(E$ group $)$

Fig. 4. This is a liner regression of the change of temperatures in each groups. A group: temperature $=25.986-0.012 \times$ distance $\left(R^{2}=0.61\right)$. B group: temperature $=26.55-0.016 \times$ distance $\left(R^{2}\right.$ $=0.726)$. C group: temperature $=30.679-0.047 \times$ distance $\left(R^{2}\right.$ $=0.596)$. $\mathrm{D}$ group: temperature $=34.765-0.01 \times$ distance $\left(\mathrm{R}^{2}=\right.$ 0.672). E group: temperature $=37.582-0.142 \times$ distance $\left(R^{2}=\right.$ 0.729). A group: RT, B group: $R T \pm 1^{\circ} \mathrm{C}, \mathrm{C}$ group: $\mathrm{RT} \pm 5^{\circ} \mathrm{C}, \mathrm{D}$ group: $\mathrm{RT} \pm 10^{\circ} \mathrm{C}, \mathrm{E}$ group: $\mathrm{RT} \pm 15^{\circ} \mathrm{C}$.

\section{Discussion}

In performing the major surgery, the infusion of fluids at a room temperature has been considered an important factor for a loss of the temperature. That is, when the fluids of $20^{\circ} \mathrm{C}$ in temperature were infused at a dose of $53 \mathrm{ml} / \mathrm{kg}$, the mean temperature has been reported to be decreased by $1^{\circ} \mathrm{C}$ [14]. In general, a decrease of the mean body temperature of approximately $0.5-1.0^{\circ} \mathrm{C}$ can be tolerated. This can also be overcome with the use of other methods. In cases in which the body temperature was decreased by more than $0.5-$ $1.0^{\circ} \mathrm{C}$, the use of a heater is recommended [12]. The room temperature was maintained at approximately $26^{\circ} \mathrm{C}$ at a laboratory where the current experiment was performed. This is a condition which was close proximity to the temperature which has generally been recommended for an operation room.

A heater which was used to maintain the temperature of fluids at $40^{\circ} \mathrm{C}$ was a heater which generates the heat using a plate of the electrical circuit. Types of a heater include the product where a disposable tube was passed through the heated tube or warm water or that where the heated water surrounds the fluids which were infused. Besides, there is also a high-heat efficiency heater which generates the heat using a plate of the electrical circuit [11]. A water-based product 
has a large volume. A tube through which fluids pass cannot be detached. A high-fever efficiency heater does not use the water. Accordingly, the mobility and size can be minimized. For this reason, it was used for the current experiment. Also in the current study, regarding the heating performance of this heater, it was confirmed that the heating was done at a temperature of approximately $40^{\circ} \mathrm{C}$.

Factors affecting the temperature of fluids which are infused to patients include the initial temperature of fluids, the rate at which fluids are infused, the temperature of surroundings to which a venous line was exposed, i.e., the length of a venous line following the passage of a heater. Of the factors affecting the temperature of fluids infused to patients, according to studies, despite the difference in the temperature from a room temperature, the temperature of fluids in the areas which were remote at a distance of $1 \mathrm{~m}$ showed no great differences. In the current study, the body temperature was not directly measured. If cool fluids should be infused, however, the central temperature would be decreased to a greater extent than the peripheral one [15]. For instance, if fluids with a temperature of $4^{\circ} \mathrm{C}$ should be infused, the central temperature would be decreased by $2.5 \pm 0.4^{\circ} \mathrm{C}$ but the peripheral one would be decreased by $1.3 \pm 0.2^{\circ} \mathrm{C}$. This indicates that it is risky to determine the degree of temperature lowering based on the peripheral temperature.

The rate at which fluids are infused can cause a great change in the body temperature in association with the amount of fluids which are infused during a short-term period. Accordingly, Schmidt et al. [14] reported that it is important to add the temperature in cases in which the amount of infusion of fluids was increased during a long-term period. In adult subjects, if the rate at which fluids are infused should be approximately $0-2 L / h$, this would have no great effect on the mean temperature. Accordingly, a heater is not necessary [12]. As a result of the current study, a saline showed a shorter time which elapsed until an outlet temperature reached a target temperature of $40^{\circ} \mathrm{C}$ as the flow rate of a saline was increased. By contrast, the maximal temperature was relatively shorter. Besides, until the temperature of fluids reached the final outlet of a venous line, the temperature was well maintained as the flow rate was increased. In association with this, according to Jung et al. [13] and Schmidt et al. [14], in the purified solution, the degree of temperature elevation was increased depending on the flow rate. The degree of temperature lowering was decreased as the flow rate was accelerated.

The final factors determining the final temperature of fluids which are infused to patients include the initial temperature of fluids, the rate at which fluids are infused and the length of a venous line which was exposed to the atmosphere following the departure from a heater. As shown in the current study, the changes in the temperature depending on the rate at which a saline was infused might originate from a timedependent loss of the heat energy depending on the time during which fluids are exposed to a room temperature in a venous line. Woolnough et al. [16] reported that the body temperature was decreased by approximately $0.2-0.6^{\circ} \mathrm{C}$ following the infusion of fluids at a room temperature in patients who underwent Caesarean section. This decrease was shown to have a higher degree than the use of a heater. Besides, of these patients, 32\% perceived a chil. The occurrence of chilling showed no great changes as compared with the use of a heater. In general, fluids whose temperature was raised by a heater should maintain the temperature which is higher than $32^{\circ} \mathrm{C}$, a threshold temperature at which patients can elevate the body temperature using a chill [17] In the current study, with the application of this threshold temperature, a saline did not meet criteria of $>32^{\circ} \mathrm{C}$ as mentioned above in the areas which were $1 \mathrm{~m}$ remote from an outlet within a range of $100-1,400 \mathrm{ml} / \mathrm{h}$. Only at a flow rate of $2,100 \mathrm{ml} / \mathrm{h}$, the temperature of fluids met these criteria. These results were not in agreement with the reports, made by Jung et al. [13], that the clinically acceptable heating effect was shown within a range of $450-5,000 \mathrm{ml} / \mathrm{h}$. The reasons are that Jung et al. conducted a study by surrounding a venous line with a heat-sealing material. In the current study, however, a venous line was exposed to a room temperature. This is assumed to cause the above-stated difference. Based on the difference in these experimental methods, another factor decreasing the temperature of fluids is the adjacent temperature. In cases of an exposure to a room temperature, in which the length of a venous line reached $145 \mathrm{~cm}$ at a rate of 1,200-3,000 ml/h, the heating efficiency was greatly decreased [14]. Therefore, the use of coaxial type of a heater surrounding a venous line with a heat-sealing material would be effective. Also in selecting the types of a heater, an exposure to a room temperature should be considered [18].

Following the passage of a heater, when the measurement was done in the same distance, the difference in the temperature of fluids depending on the flow rate arises from a loss of the heat occurring in a venous line and thermal conduction. Therefore, this is an important factor that should be considered in heating fluids. In a venous line with the same length, as the flow rate was relatively higher, an exposure time to atmosphere was shortened. This led to a decreased heat loss. As the flow rate was relatively lower, an exposure time to atmosphere was prolonged. This led to an increased heat loss. In general, the quality of material of a venous line which is used in a clinical setting is polyvinyl chloride, and its thermal conductivity is $0.25 \mathrm{kcal} / \mathrm{m} / \mathrm{h} /{ }^{\circ} \mathrm{C}$. Due to the overall surface area of a venous line and thermal exposure due to the infusion rate, a heat loss promptly appears [19]. According to Uhl et al. [20], in cases in which a saline is used, at an infusion rate of $<2,000 \mathrm{ml} / \mathrm{h}$, due to a room temperature in the 
adjacent area, the temperature exceeding $33^{\circ} \mathrm{C}$ cannot be maintained. In cases in which the infusion rate was relatively lower, fluids can be completely heated. Following the departure from a heater, however, the equilibrium can be well reached. In cases in which the infusion rate was relatively higher, despite an incomplete heating, an equillibrium with a room temperature is achieved to a lesser extent. This can offset an incomplete heating. Accordingly in cases in which heated fluids are infused at a lower infusion rate, the temperature get further closer to a room temperature. At least, at an infusion rate of $750-1,000 \mathrm{ml} / \mathrm{h}$, fluids which were stably heated can be provided. In cases in which Utratherm ${ }^{\mathrm{TM}}$ is used, the infusion rate can reach a value of $500 \mathrm{ml} / \mathrm{h}$. As compared with the general types of a heater, there is a higher degree of the accessibility $[21,22]$.

In cases in which the infusion rate is consistent, the degree of temperature lowering is abruptly decreased as the difference between outlet temperature and the adjacent temperature was relatively greater. As the time of exposure to the adjacent temperature was increased according to the length of a venous line, the degree of temperature lowering was also increased. At an infusion rate of $100 \mathrm{ml} / \mathrm{h}$, in the infusion tube of $1 \mathrm{~m}$ in length, with no respect to the degree of outlet temperature, in a similar manner to the adjacent temperature, the temperature was lowered. Accordingly in cases in which a fluid therapy is performed for pediatric patients, there would be a lack of the heating effect unless special attention should be paid to the length of a venous line. According to the current study, to make sure that the temperature of fluids should not be lowered to a room temperature of $\pm 1^{\circ} \mathrm{C}$ in the adjacent temperature, the minimal length of a venous line should be $25 \mathrm{~cm}$. These results were in agreement with the reports, made by Faries et al. [21], that the temperature of fluids could be maintained in cases in which a heater was remote at a distance of $<25 \mathrm{~cm}$. These reports well illustrated that a heater should be placed in a more accessible manner to patients.

According to these results, as the methods for maintaining the temperature of fluids which were heated, the length of a venous line through which heated fluids passed should be minimized. A loss of the heat energy to the adjacent environment at a lower infusion rate should be prevented. Following the passage of fluids through a heater, until they reached patients, a venous line should be surrounded with a heatsealing material. If the infusion rate should be increased, the temperature lowering of heated fluids could be prevented. But a prompt infusion rate is unfavorable towards pediatric patients. These methods are assumed to have a marked advantage in adult patients or those with trauma or surgery for whom a massive amount of fluids should be promptly administered.

In the current study, in cases in which the infusion rate was relatively lower, the outlet temperature was significantly elevated. In other words, in cases in which the flow rate was relatively lower, the final outlet temperature was relatively higher. Particularly at a flow rate of $200 \mathrm{ml} / \mathrm{h}$, the final outlet temperature reached a value of $46.29^{\circ} \mathrm{C}$. At all flow rates, the final outlet temperature was higher than $42^{\circ} \mathrm{C}$. Although this was a temporary time of $1-2$ seconds, it could be considered as the problem in cases in which blood is used. There are several reports about the final outlet temperature and its duration which can be permitted. Human RBCs tolerate the temperature which is almost close to $45^{\circ} \mathrm{C}$ during a long-term period with no respect to the cellular activiy. At a temperature of $>45^{\circ} \mathrm{C}$, the protein degeneration of RBC membrane occurs and this leads to the occurrence of hemolysis. The degree of hemolysis is increased in a linear manner depending on the degree of exposure temperature and time [23,24] Accordingly, although the current study was conducted in fluids only, from a time perspective, however, regarding how the temporary high temperature corresponding to several seconds affects the blood, further studies will be conducted.

In conclusion, with the use of a portable rapid fluid heater, a saline was heated at various flow rates. Then, the temperature elevating effects were tested. According to this, at an infusion rate of $100-2,100 \mathrm{ml} / \mathrm{h}$, within a short period of time of approximately 2 minutes, the effects of fluid heating were shown at a temperature of more than $40^{\circ} \mathrm{C}$. In the temperature reaching patients, there was a difference depending on the length of a venous line and the infusion rate. To make sure that the body temperature should be maintained, for the maintenance of the optimal level of the elevation of fluid temperature, the length of a venous line from the outlet of a heater should be minimized within 25 $\mathrm{cm}$. It also seems that a venous line should not be directly exposed to the external environment. A fluid heating with a heater could not elevate the body temperature of patients. In patients who are infused with a massive amount of fluids, however, hypothermia due to fluids can be prevented [25].

\section{Acknowledgements}

This study was supported by a grant of the Korea Healthcare technology R\&D Project, Ministry for Health, Welfare \& Family Affairs, Republic of Korea (A084177).

\section{References}

1. Platts-Mills TF, Stendell E, Lewin MR, Moya MN, Dhah K, Stroh G, et al. An experimental study of warming intravenous fluid in a cold environment. Wilderness Environ Med 2007; 18: 177-85.

2. Tintinalli JE, Krome RL, Ruiz E. Emergency medicine: a comprehensive study guide. 2nd ed. New York, McGraw- 
Hill Book Co., 1985, pp 748-53.

3. Aslam AF, Aslam AK, Vasavada BC, Khan IA. Hypothermia: evaluation, electrocardiographic manifestations, and management. Am J Med 2006; 119: 297-301.

4. Arthurs Z, Cuadrado D, Beekley A, Grathwohl K, Perkins J, Rush $R$, et al. The impact of hypothermia on trauma care at the 31st combat support hospital. Am J Surg 2006; 191: 610-4.

5. Martin RS, Kilgo PD, Miller PR, Hoth JJ, Meredith JW, Chang MC. Injury-associated hypothermia: an analysis of the 2004 National Trauma Data Bank. Shock 2005; 24: 114-8.

6. Brieva J, McFadyen B, Rowley M. Severe hypothermia: challenging normal physiology. Anaesth Intensive Care 2005; 33: 662-4.

7. Kurz A, Sessler DI, Lenhardt R. Periopoerative normothermia to reduce the incidence of surgical-wound infection and shorten hospitalization. N Engl J Med 1996; 334: 120916.

8. Sessler DI. Mild perioperative hypothermia. N Engl J Med 1997; 336: 1730-7.

9. Torossian A. Thermal management during anaesthesia and thermoregulation standards for the prevention of inadvertent perioperative hypothermia. Best Pract Res Clin Anaesthesiol 2008; 22: 659-68.

10. Redick LF, Hill RF, Murray WJ. Intravenous fluid warming with microwave ovens: a review and guidelines for use. Regional Anesth 1988; 13: 112-6.

11. Ohtsuka N, Yamakage M, Chen X, Kamada Y, Namiki A. Evaluation of four techniques of warming intravenous fluids. J Anesth 2002; 16: 145-9.

12. Horowitz PE, Delagarza MA, Pulaski JJ, Smith RA. Flow rates and warming efficacy with Hotline and Ranger blood/fluid warmers. Anesth Analg 2004; 99: 788-92.

13. Jung SW, Han TH, Lee JY, Kwak IS, Jung MH, Won RS, et al. Performance characteristics of high efficiency fluid and blood warmer using print circuit board heater at various flow rates. Korean J Anesthesiol 2006; 51: 598-605.

14. Schmidt JH, Weyland W, Fritz U, Brauer A, Rathgeber $J$, Braun U. The comparative effectiveness of different infusion and blood warming methods. Anaesthesist 1996; 45: 1067-74.

15. Rajek A, Greif R, Sessler DI, Baumgardner J, Laciny S, Bastanmehr $\mathrm{H}$. Core cooling by central venous infusion of ice-cold $\left(4^{\circ} \mathrm{C}\right.$ and $\left.20^{\circ} \mathrm{C}\right)$ fluid. Anesthesiology 2000; 93 : 629-37.

16. Woolnough M, Allam J, Hemingway C, Cox M, Yentis SM. Intra-operative fluid warming in elective caesarean section: a blinded randomised controlled trial. Int J Obstet Anesth 2009; 18: 346-51.

17. Russell WJ. A review of blood warmers for massive transfusion. Anaesth Intensive Care 1974; 2: 109-30.

18. Schnoor J, Weber I, Macko S, Heussen N, Rossaint R. Heating capabilities of the Hotline and Autoline at low flow rates. Paediatr Anaesth 2006; 16: 410-6.

19. Presson RG Jr, Bezruczko AP, Hillier SC, McNiece WL. Evaluation of a new fluid warmer effective at low to moderate flow rates. Anesthesiology 1993; 78: 974-80.

20. Uhl L, Pacini D, Kruskall MS. A comparative study of blood warmer performance. Anesthesiology 1992; 77: 1022-8.

21. Faries G, Johnston C, Pruitt KM, Plouff RT. Temperature relationship to distance and flow rate of warmed i.v. fluids. Ann Emerg Med 1991; 20: 1198-200.

22. Lee JH, Mintz PD. Performance characteristics of Ultratherm ${ }^{\text {TM }}$ fluid warmer. Anesth Analg 1993; 77: 1271-4.

23. Chalmers C, Russell WJ. When does blood haemolyse? A temperature study. Br J Anaesth 1974; 46: 742-6.

24. Checcucci A, Olmi R, Vanni R. Thermal haemolytic threshold of human erythrocytes. J Microw Power Electromagn Energy 1985; 20: 161-3.

25. Insler SR, Sessler DI. Perioperative thermoregulation and temperature monitoring. Anesthesiol Clin 2006; 24: 82337. 